\title{
Influence of Intellectual Capital, Knowledge Sharing, and Innovation on Indonesian Startup Companies: A Development of Conceptual Framework
}

\author{
Iwan Inrawan Wiratmadja, Augustina Asih Rumanti, and Sarif Mubdi Jantika
}

\begin{abstract}
The number of failed startup companies greatly exceed the ones that managed to survive. Small and medium company's inability to survive in business competition is generally caused by the company's weak performance. In the era of knowledge-based economy, intangible resources are deemed crucial for companies to be focused on. Startup is a kind of company that relies heavily on intangible assets.

Intellectual capital is one form of intangible resources that can be managed by the company to gain a competitive advantage. Based on the existing literature, it can be concluded that there is a gap between intellectual capital and performance management for startup to survive. The performance of the company's business is fundamentally driven by competitive advantage. To be able to create a competitive advantage, company should focus on knowledge-sharing activity as it would create a platform for innovation, thus enhances the whole performance. This study attempts to fill that gap by building a model that shows the effect of intellectual capital on company performance through the process of knowledge sharing and innovation.

The results show that there are significant direct relationships from human capital to structural capital and innovation; from structural capital to relational capital; from relational capital to knowledge sharing; and from innovation to company performance. There are on the other hand, indirect relationship between human capital and company performance through structural capital, relational capital, knowledge sharing, and innovation process. Significant mediating effect is shown by the variable of innovation in the relationship between knowledge sharing and the company performance. The results of this study are expected to become an evaluation and improvement framework for startup companies in Indonesia.
\end{abstract}

Index Terms-Intellectual capital, knowledge sharing innovation, performance.

\section{INTRODUCTION}

Indonesia was positioned at the second rank of top three biggest countries with the most startup financing deals that generates eleven deals worth $\$ 3.5$ million in the second quarter of 2015. Singapore peaked at the first position, while Malaysia being the second runner-up [1]. Based on technology news portal "Dailysocial.net", the number of Indonesian startup companies in 2015 reached more than 1500 and is believed to expand. The Indonesian Association

Manuscript received February 10; revised May 13, 2018.

Iwan Inrawan Wiratmadja and Sarif Mubdi Jantika are with Department of Industrial Engineering, Bandung Institute of Technology, Indonesia (email: iwan@1spitb.org, sarif.mj@gmail.com).

Augustina Asih Rumanti is with Departement of Industrial Engineering, Bandung Institute of Technology, Indonesia and Department of Industrial Engineering, Telkom University, Indonesia (email: augustinaar@gmail.com). of Internet Provider (APJII) predicted that e-commerce will contribute \$26 million to the country's GDP [1].

In the era of knowledge-based economy, intangible resources and competencies are crucial factors for a company to sustain in a dynamic environment [2]. Barney in 1991 stated that intangible asset is an asset that can be used to create a sustainable competitive advantage and a good financial performance [3]. During the process of theoretical building to describe intangible theory, accounting theory and analogy argued that intangible theory has evolved to become a broader concept i.e. intellectual capital [4]. Startups are a kind of business that rely on intangible factors (business formula, managerial capability and human resource), hence every single management approach needs to be based on intellectual capital [5].

ICM Gathering has developed a definition for intellectual capital as a form of knowledge that can be converted to profit for company [6]. Schiuma in 2001 argued that to gain, develop, and manage intellectual capital in an organization, requires a set of knowledge-management activities [7]. A company that succeeds in creating a competitive advantage will be able to elevate its productivity and innovation capability through the process of innovative-planned knowledge management [8].

Knowledge sharing can be defined as efforts conducted so that the knowledge can be available to the member of an organization [9], [10]. Intellectual capital has a positive influence to knowledge sharing in small and medium enterprises (SME), which demonstrates the importance of SMEs paying a deeper attention to improving their knowledge sharing process in order to create a path for innovation leading to improvement in the overall performance [11]. Knowledge sharing positively influences the increase in company performance either directly or through mediating effect from innovation [12]. This is in accordance with a research explaining that the employee willingness to give or receive knowledge can help a company to innovate [13].

A company's innovation performance is affected by the whole components in intellectual capital [14]. The ability to innovate is heavily dependent on company's intellectual capital or ability to manage its possessed knowledge resources [15]. The concept of knowledge can be linked with innovation through the process of knowledge creation [16]. Knowledge creation is defined as a continuous process to gain a new context, perspective, and knowledge with an aim to avoid obstacles or problems in the future [17]. Innovation is an implementation of idea in a product, process, or other aspect under the context of organizational activity that can add value. Innovation can be set as a parameter for 
Performance on a product/service; or a basis to fix and develop a product in the future [18]. The process of new product or service adoption will enhance one's competitive advantage and overall consumer-based profit [19]. The understanding of business model design that is based on consumer need and technology utilization can increase company's competitive advantage [20].

\section{LITERATURE REVIEW}

\section{A. Intellectual Capital}

Intellectual capital as an accumulation of company ownership includes: a number of collective knowledge, information, technology, intellectual property rights, experience, organizational learning, competencies, communication system among team, relationship with consumers, and brands that can create value for company [14]. Intellectual capital is intellectual materials that have been formalized, captured, and developed to generate profit by producing assets with higher value [21].

Intellectual capital can be seen as an economic value out of the three intangible assets i.e. human capital that includes skills and competencies created and owned by individuals; structural capital that covers existing capabilities and knowledge owned by the organization; and relational capital that includes all external relationships with stakeholders [22]. Human capital is a central factor in an organization as it serves as a source for innovation and strategic renewal, either from brainstorming process in research laboratory, idea creation in workplace, disposal of past work archives, engineering a new process, self-skill development or improve a new prospect on sales strategy. The essence of human capital is the sharpness of mindset for organization's members [23]. Human capital is an accumulation of individual capability and responsibility to resolve consumer's problems [11]. Human capital is likewise defined as employees' skill and capability that create value for company, which include knowledge, experience, and loyalty to organization [24]. Structural capital is all company's components that are immovable including hardware, software, database, organization structure, patent, and brand [14]. Structural capital can be defined as non-humane knowledge dispersed through database, process, strategy, routine, organization culture, brand, and copyright [25]. Edvinsson and Malone in 1997 described structural capital as intangible asset that cannot be brought home when employees return home or leave the organization [26]. Within structural capital, lies intellectual property that is perceived more tangible than other structural capital components. Intellectual capital involves patent, copyright, trademark, and other components, whose value can be measured [27]. Relational capital is defined as an integrated relationship between company and consumer so that it can adjust its culture to market orientation [11]. Relational capital is a work relationship from an enterprise that includes consumer, supplier, and other inter-integrated entity [14].

\section{B. Knowledge Sharing}

Knowledge sharing can be defined as individual learning activities in an organization, including the integration in implementing the knowledge process to intellectual capital. Knowledge must be well-organized to benefit the company.
The fact that knowledge can appear in various forms i.e. tacit, explicit, formal or informal, proves that direct interaction is a primary understanding of tacit-knowledge sharing [12], [13], [28]. The key of tacit-knowledge sharing is the willingness and capacity from each individual to share what they know and the learned know-how [12]. Individual willingness to change from mistake is one of the success factors in tacit-knowledge sharing [28].

\section{Innovation}

In reacting to the incremental business competition, technology development, and the declining of product lifecycle, companies are expected to innovate even faster [12]. The more competent a company, the better innovation will be materialized [14]. Innovation is a result of the integration of knowledge and technology [14]. The ability to innovate can be observed from company involvement in supporting novel ideas, inventions, experiments, and creative processes that enable renewal [29].

\section{Performance}

Business performance is a description of the level of task completion from a goal or business targets based on the result at the end of business period [30]. Company performance is an achievement that can be measured through two perspectives i.e. operational and financial [12].

Operational achievement is reflected through five indicators i.e. service to consumer, cost management, quality management, level of productivity, and asset management [12]. There are four indicators used to measure financial achievements i.e. average ROI (Return on Investment), average profit, profit growth rate, and average return on goods/service's sales [12].

\section{RESEARCH METHODOLOGY}

\section{A. Model and Hypotheses in Research}

The purpose of this research is to identify the relationship of intellectual capital, knowledge sharing, and innovation to the company performance, and to identify the significance of the influencing factors in the developed model. Research hypothesis is a result of initial assumption against a problem that will be analyzed and tested through data. Research hypothesis is formed through previous researches. The hypotheses in this research model are:

H1 : Human Capital positively influences Structural Capital

H2 : Human Capital positively influences Relational Capital

H3 : Human Capital positively influences Innovation

H4 : Structural Capital positively influences Relational Capital

H5 : Structural Capital positively influences innovation

H6 : Relational Capital positively influences

H7 : $\quad \begin{aligned} & \text { innovation } \\ & \text { Relational Capital positively influences }\end{aligned}$ Knowledge Sharing

H8 : Knowledge Sharing positively influences innovation 
H9 : Knowledge Sharing positively influences company performance

H10 : Inovation positively influences company performance

\section{B. Research Strategy}

A case study was conducted for this research. Analysis was conducted on individuals working in an Indonesian startup firm. The respondents in this study are the top/middle employees. Data collection is conducted through convenience sampling method, which relies on low difficulty in gaining the data, with total of 70 questionnaires that can be utilized for further analysis.

The variables in this research are human capital, relational capital, structural capital, innovation, knowledge engineering, and firm performance.

The indicators for human capital are employee's capability, employee's knowledge, employee's experience, and employee's loyalty; The indicators for structural capital are database, business process, company strategy, company's routine, organizational culture, brand, and copyrights; The indicators for relational capital are company-consumer relationship, company-supplier relationship, and company-(other) entity relationship; Knowledge engineering can be explained through tacit knowledge (experience, skills, and learning from past mistakes), explicit knowledge (collecting and using format report from document, training and development program, and IT systems); The indicators for innovation are new ideas, new discovery, experiment, and creative process; While company performance can be measured through operational and financial perspective. The following Figure 1 illustrates the research model.

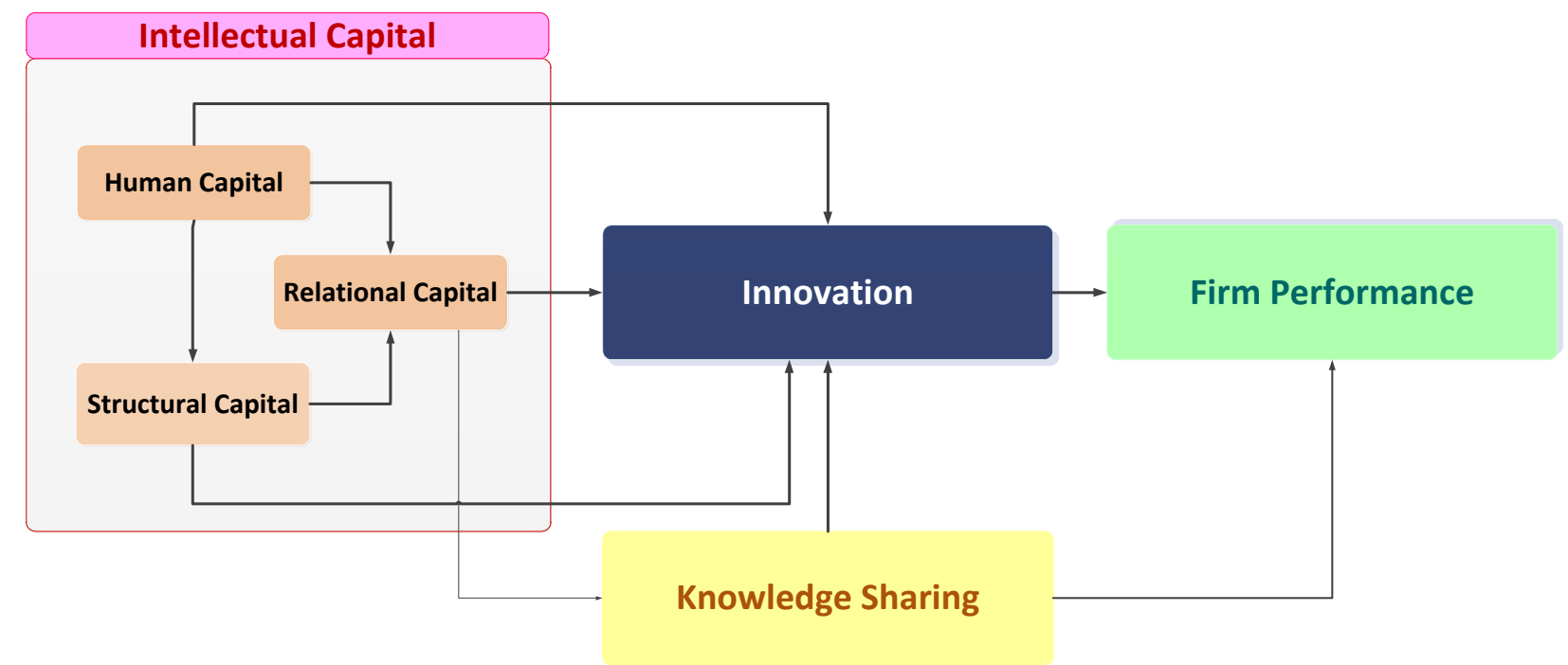

Fig. 1. Research model.

\section{ANALYSIS}

\section{A. Measurement Validation Analysis}

Reliability test indicates how far the stability and consistency of a measurement is in a test. In this research, it is conducted through Cronbach's Alpha. The minimal limit of Cronbach's Alpha in reliability test has to be $>0.6$ [31]. The result from statistical calculation using software SPSS 19.0 shows that all construct exceed 0.6 and is shown in Table 1.

TABLE I: CRONB ACH'S ALPHA SCORE

\begin{tabular}{|l|c|c|}
\hline \multicolumn{1}{|c|}{ Endogen Construct } & Cronbach's Alpha Score & Result \\
\hline Human Capital & 0,792 & Reliable \\
\hline Structural Capital & 0,849 & Reliable \\
\hline Relational Capital & 0,699 & Reliable \\
\hline Knowledge Sharing & 0,786 & Reliable \\
\hline Innovation & 0,794 & Reliable \\
\hline Firm Performance & 0,904 & Reliable \\
\hline
\end{tabular}

Validity test is conducted to identify how fit the measurement is to measure its construct by correlating the score from each question point with total score from the questions that form the indicator.

The questionnaire in this research utilized ordinal data through Likert scale, thus validity parameter being used is a non-parametric Spearman correlation (r-calc) that is compared with r-value from table with a certain degree of trust $(\alpha)$. Ordinal scale provides more information than nominal scale by ordering the categories [31]. The result from questionnaire's validity test indicates that all questions are valid to measure their variable because the conclusion is to reject the $\mathrm{H} 0$ (r-calc $\geq$ r-table). This hypotheses rejection show that all questions have a significant correlation to the measured variable, hence this questionnaire is considered good and therefore can be used furthermore.

Next validation measuring instrument can be seen from the cross loading where the value of cross loading of an indicator should be higher than the value of cross loading other indicators in order to be valid. From the data processing, it is known that there are several indicators that have a value in a variable cross loading that is smaller compared to the value of the other manifest variables. These indicators should be re-calculated. However since there are several variables manifest that will be terminated should the re-calculation occurs, thus changing the model, this research sided with fitting model over the re-calculating.

There are many indicators used to measure variables. Invalid manifest this can be caused by items of statements made to an indicator variable, which cannot explain its 
construct. Another reason would be the people who responded to the questionnaire, who do not understand the purpose of the statements contained in the indicator, so that false interpretation transpired.

\section{B. Analysis of Research Variables}

The analysis for PLS-SEM result includes two processes that have different assessment either on outer model or inner model. The first step is to conduct validity test and reliability test according to the model. The score for Composite Reliability and Cronbach's Alpha can be used to evaluate the reliability of research model. The model is considered reliable if the score is higher than 0.7 yet is considered unreliable of the score goes below 0.6 [32].

Based on these measurements, it can be inferred that the reliability for the six research variables is acceptable. The significance test for research model can be described as determining the loading estimation score from each indicator for the measured variable. The loading score for each indicator can then be compared with t-statistics to infer its significance level. The loading score is considered good when it exceeds 0.7 , while it is recommended to eliminate a score below 0.4 .

The process of eliminating an indicator can also be based on p-value, where $>0.05$ means that the measured indicator is not significant enough in measuring its latent variable, thus can be considered in elimination [32]. Table II shows the results of data computation using Partial Least Square (PLS) and Fig. 2 shows the result computation from SEM-PLS.

TABLE II: PLS RESULT

\begin{tabular}{|c|c|c|c|c|c|}
\hline Endogen Construct & AVE & CR & $\mathrm{R}^{2}$ & T-Statistic & Significantly \\
\hline Human Capital & 0,755 & 0,871 & 0,933 & 11,70 & $\sqrt{ }$ \\
\hline Structural Capital & 0,850 & 0,891 & 0,822 & 5,78 & $\sqrt{ }$ \\
\hline Relational Capital & 0,761 & 0,822 & 0,906 & 10,66 & $\sqrt{ }$ \\
\hline Knowledge Sharing & 0,864 & 0,879 & 0,946 & 8,03 & $\sqrt{ }$ \\
\hline Innovation & 0,833 & 0,872 & 0,965 & 12,55 & $\sqrt{ }$ \\
\hline Firm Performance & 0,703 & 0,932 & 0.885 & 11,22 & $\sqrt{ }$ \\
\hline
\end{tabular}

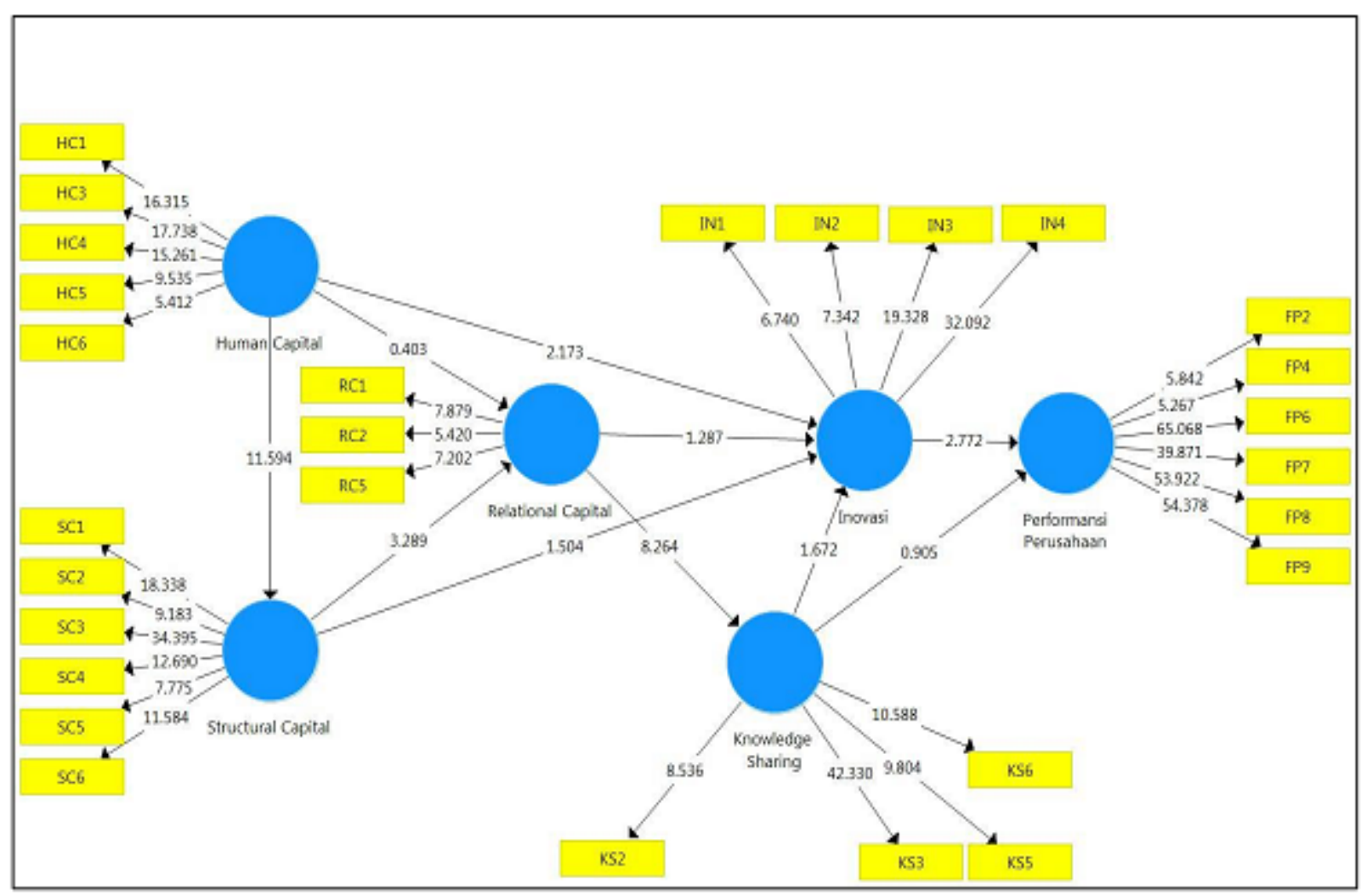

Fig. 2. SEM-PLS result.

R-square values of the Human Capital is at 0,933 which means the variance that can be explained by its manifestation variable that is equal to 93.3 and $6.7 \%$ is explained by other factors; R-square for Structural Capital is at 0,822 which means the variance that can be explained by its manifestation variable that is equal to $82,2 \%$ and $17,8 \%$ is explained by other factors; R-square for Relational Capital is at 0,906 which means the variance that can be explained by its manifestation variable that is equal to $90,6 \%$ and $9,4 \%$ is explained by other factors; R-square for Innovation is 0,946 which means the variance that can be explained by its manifestation variable that is equal to $94,6 \%$ and $5,4 \%$ is explained by other factors; R-square for Knowledge Sharing is 0,965 which means the variance that can be explained by its manifestation variable that is equal to $96,4 \%$ and $3,6 \%$ is explained by other factors; R-square for Firm Performance is 0,885 which means the variance that can be explained by its manifestation variable that is equal to $88,5 \%$ and $11,5 \%$ is 
explained by other factors.

\section{E. Research Hypothesis Analysis}

Result testing the hypothesis of this research, can be seen from the value of t-statistic resulting from the path on the coefficient of. A limit for this research is worth $\pm 3,182$ with the value of $\mathrm{v}=3$ and $\alpha / 2=0,0025$, if the value in range \pm 3,182 , the result is then to accept $\mathrm{H}_{0}$ and reject $\mathrm{H}_{1}$, but if above $\pm 3,182$ then the result is accept $\mathrm{H}_{1}$ and $\mathrm{H}_{0}$ is rejected. All hypotheses in this research are accepted.

\section{CONCLUSION}

Based on the stages that have been done before in this study, especially in data processing and analysis, we can conclude a few things:

- There is a direct relationship that is significant in all the variables involved i.e. human capital, structural capital, relational capital, innovation, knowledge sharing and firm performance.

- There is a significant-mediating effect shown by the variable innovation in the relation between knowledge sharing and firm performance.

- Increasing firm performance can be done by implementing human resource strategies that hire employees with startups characteristics, increasing the employees' intelligence through vocational trainings, injecting the employees with a mindset that focuses on consumer satisfaction, and guiding the employees to be open regarding business process to enable innovation.

For further research can be investigated the concept of innovation that play a role in organizational performance, namely whether the concept of innovation that comes from internal company, external company or role of both. In addition, it is necessary also to examine the sources of knowledge sharing used to achieve innovation to measure the performance of companies, especially for star-up companies.

\section{ACKNOWLEDGMENT}

Authors would like to thank Bandung Institute of Technology and Telkom University for providing the supporting facility in conducting the research. Authors would also like to thank the owner of star-up firm for the opportunity given in conducting the research by providing data so the research could be seamlessly conducted.

\section{REFERENCES}

[1] D. A. Candraningrum, "Model bisnis baru di era media Baru," in Proc. International Conference of Communication, Industry and Community, pp. 411-424, 2016.

[2] Z. Wang, N. Wang, and H. Liang, "Knowledge sharing, intellectual capital and firm performance," Management Decision, vol. 52, no. 2, pp. 230-258, 2014.

[3] A. R. Belkaoui, "Intellectual capital and firm performance of multinational firms: A study of the resource-based and stakeholder views," Journal of Intellectual Capital, vol. 4, no. 2, pp. 215-226, 2003.

[4] M. A. Ortiz, "Intellectual capital (intangible assets) valuation considering the context," Journal of Business \& Economics Research vol. 4, no. 9, 2006.

[5] B. M. Rodriguez, "A new insight into the valuation of start-ups: Bridging the intellectual capital gap in venture capital appraisals,' Electronic Journal on Knowledge Management, vol. 1, no. 2, pp. 125-138, 2003.
[6] P. H. Sullivan, "Profiting from intellectual capital," Journal of Knowledge Management, vol. 3, no. 2, pp. 132-143, 1999.

[7] B. Marr, O. Gupta, S. Pike, and G. Roos, "Intellectual capital and knowledge management effectiveness," Management Decision, vol. 41, no. 8, pp. 771-781, 2003.

[8] A. Gupta and J. McDaniel, "Creating competitive advantage by effectively managing knowledge: A framework for knowledge management," Journal of Knowledge Management Practice, 2002.

[9] D. Paulin and K. Suneson, "Knowledge transfer, knowledge sharing and knowledge barriers - Three blurry terms in KM electronic," Journal of Knowledge Management, vol. 10, no. 1, 2012.

[10] R. Du, S. Ai, and Y, Ren, " Relationship between knowledge sharing and performance: A survey in Xi'an, China," Elsevier Expert Systems with Applications, vol. 32, pp. 38-46, 2007.

[11] R. Ngah and A. R. Ibrahim, "The influence of intellectual capital on knowledge sharing: Small and medium enterprises' perspective. Communications," IBIMA, vol. 2011, no. 444770, p. 13, 2011.

[12] Z. Wang and N.Wang, "Knowledge sharing, innovation and firm performanc," Expert Systems with Applications: An International Journal Archive ,vol. 39, no. 10, pp. 8899-8908, 2012.

[13] H. F. Lin, "Knowledge sharing and firm innovation capability - An empirical study," International Journal of Manpower, vol. 28, no. 3/4, pp. 315-332, 2007.

[14] M. Zerenler, S. B. Hasiloglu, and M. Sezgin, "Intellectual capital and innovation performance: Empirical evidence in the turkish automotive supplier," Journal. Technol. Manag. Innov. vol. 3, no. 4, 2008.

[15] M. Subramaniam and M. A. Youndt, "The influence of intellectual capital on the types of innovative capabilities," Academy of Management Journal, vol. 48, no. 3, pp. 450-463, 2005.

[16] I. Nonaka, "A dynamic theory of organizational knowledge creation organization science," vol. 5, pp. 14-37, 1994.

[17] R. Kamasak and B. Fusun, "The influence of knowledge sharing on innovation," European Business Review, vol. 22, no. 3, pp. 306-317, 2010.

[18] C. Greenhalgh and M. Rogers, Innovation, Intellectual Property, and Economic Growth, Princeton University Press, 2016.

[19] A. Kalkan, O. C. Bozkurt, and M. Arman, "The impacts of intellectual capital, innovation and organizational strategy on firm performance," Procedia - Social and Behavioral Sciences, vol. 150, pp700-707, 2014.

[20] D. J. Teece, "Business models, business strategy and innovation," Long Range Planning, vol. 43, pp. 172-194, 2010.

[21] A. Sharabati, S. N. Jawad, and N , Bontis, "Intellectual capital and business performance in the pharmaceutical sector of Jordan," Management Decision, vol. 48, no. 1, pp. 105-131, 2010.

[22] F. Rogo, L. Cricelli, and M. Grimaldi, "Assessing the performance of open innovation practices: A case study of a community of innovation," Technology in Society, vol. 38, pp. 60-80, 2014.

[23] N. Bontis, W. C. C. Keow, and S. Richardson, "Intellectual capital and business performance in malaysian industries," Journal of Intellectual Capital, vol. 1, no. 1, pp. 85-100, 2000.

[24] T. A. De Silva, S. Michelle, and C. Murray, "Intellectual capital reporting: A longitudinal study of new zealand companies," Journal of Intellectual Capital, vol. 15, no. 1, pp. 157-172, 2013.

[25] S. Cabrilo, L. G. Nesic, and S. Mitrovic, "Study on human capital gaps for effective innovation strategies in the knowledge era," Journal of Intellectual Capital, vol. 15, no. 3, pp.411-429, 2014.

[26] Z. Wang, N. Wang, and H. Liang, "Knowledge sharing, intellectual capital and firm performance," Management Decision, vol. 52, no. 2, pp. 230-258, 2014.

[27] L. Bollen, P. Vergauwen, and S. Schnieders, "Linking intellectual capital and intellectual property to company performance," Management Decision, vol. 43, no. 9, pp. 1161-1185, 2005.

[28] J. S. Holste and D. Fields, "Trus and tacit knowledge sharing and use," Journal of Knowledge Management, vol. 14, no. 1, pp. 128-140, 2010.

[29] A. S. Arshad, A. Rasli, A. A. Arshad, and Z. M. Zain, "The impact of entrepreneurial orientation on business performance: A study of technology-based SMEs in Malaysia," INCOMaR 2013. Procedia Social and Behavioral Sciences, vol. 130, pp. 46-53, 2014.

[30] S. Yildiz, F. Basturk, and I. T. Boz, "The effect of leadership and innovativeness on business performance," in Proc. of the 10th International Strategic Management Conference. Procedia - Social and Behavioral Sciences, vol. 150, pp. 785-793, 2014.

[31] U. Sekaran and R. Bougie, Research Methods for Business: A Skill-Building Approach, 5th ed. UK: John Wiley \& Sons Ltd, 2010.

[32] J. Henseler, C. M. Ringle, and R. R. Sinkovics, " The use of partial least squares path modeling in international marketing," Advances in International Marketing, vol. 20, no. 1, pp. 277-319, 2009. 


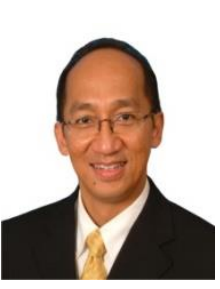

Iwan Inrawan Wiratmadja is an associate professor at Department of Industrial Engineering, Bandung Institute of Technology in Bandung, Indonesia. He received doctoral degree from Ecole Supérieure des Affaire-University Pierre Mendes France, Grenoble in 1995 in management of technology field. His current research interests are in technology and knowledge management field.

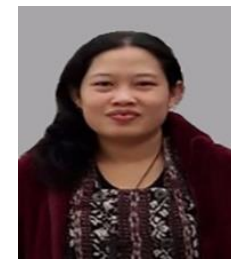

Augustina A. Rumanti is an associate professor in Industrial Engineering, Telkom University, Bandung, Indonesia. Now she is a Ph.D student in Bandung Institute of Technology. She received her master degree from Indonesia in 2009. Her current interest researchs are in the area of organization development, knowledge management, innovation system and management of technology.
Sarif Mubdi Jantika received his master dergee from Bandung Institute of Technology in 2017. His interest researchs are in the area startup enterprises and enterprise information system.

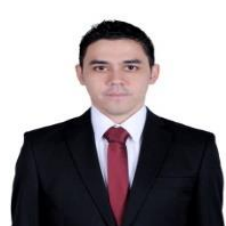

